\title{
Historiografia sobre mutualismo (1875-1914) em Portugal e no Brasil*
}

\author{
Historiography about mutualism (1875-1914) \\ in Portugal and Brazil \\ Historiografia sobre el mutualismo (1875-1914) \\ en Portugal y Brasil
}

Ronaldo Pereira de Jesus**

\begin{abstract}
Resumo: Análise da produção historiográfica acerca do fenômeno associativo mutualista em perspectiva comparada no Brasil e em Portugal, tendo em vista o fenômeno associativo em geral e o mutualismo em particular, observado como objeto de investigação histórica ao longo do século XX e como uma das principais expressões da cultura associativa dos trabalhadores urbanos no período entre 1875 e 1914.
\end{abstract}

Palavras-chave: mutualismo; cultura associativa; era dos impérios

Abstract: Analysis of historiography about the mutualist associative phenomenon in comparative perspective in Brazil and Portugal, considering the associative phenomenon in general and mutualism in particular seen as an object of historical research throughout the twentieth century and as one of the main expressions of associational culture of urban workers in the period between 1875 and 1914.

Keywords: mutualism; associational culture; the age of empires

Resumen: Análisis de la historiografía sobre el fenómeno asociativo mutualista en perspectiva comparada en Brasil y Portugal, teniendo en cuenta el fenómeno asociativo en general y el mutualismo, en particular, visto como un objeto de la investigación histórica a lo largo del siglo XX y como uno de los principales expresiones de la cultura asociativa de los trabajadores urbanos en el período entre 1875 y 1914.

Palabras clave: mutualismo; cultura asociativa; la era de los imperios

* O artigo é resultado parcial do projeto Cultura Associativa em Perspectiva Comparada: Brasil e Portugal (1870-1914); pós-doutorado realizado na Universidade de Lisboa, financiado pela Capes - Estágio Sênior (2014-2015).

** Professor Associado do Departamento de História e do Programa de Pós-Graduação em História da Universidade Federal de Juiz de Fora (UFJF). <ronaldo.jesus@ufjf.edu.br> $<$ dados biográficos/biographic data> 


\section{Mutualismo na era dos impérios}

Desde meados do século XIX, as práticas associativas difundiramse vertiginosamente criando ou recriando no mundo ocidental uma variedade significativa de sociedades científicas, clubes literários, grêmios recreativos (dramáticos, musicais, desportivos), cooperativas, sindicatos e partidos políticos. Nesse contexto, surgiram as associações de ajuda mútua, cujo objetivo era proteger os associados dos riscos que comprometiam as condições de vida dos trabalhadores, disponibilizando ajuda pecuniária em casos de doença, acidente, invalidez, velhice, prisão e morte. Frequentemente, a experiência mutualista ampliou-se para além dos objetivos básicos dos socorros e passou a preconizar também a construção de bibliotecas, a comemoração de efemérides, a publicação de jornais e livros, a instrução de jovens e crianças, a procura de emprego e o entretenimento educativo, eventualmente com fins caritativos ou filantrópicos (Ver: CEDEÑO, 1983; RECALDE, 1991; LINDEN, 1996; ROSENDO, 1996; MUNK, 1998; RALLE, 1999; DREYFUS, 2001; VISCARDI, JESUS, 2007).

As sociedades de socorros mútuos se difundiram, ao longo do século XIX, sob a influência da reflexão teórica e da prática política de intelectuais ligados às vertentes socialistas oriundas da Revolução Francesa. Saint-Simon, Robert Owen, Charles Fourier, Pierre-Joseph Proudhon e Louis Blanc são considerados os principais precursores e patronos do cooperativismo e do mutualismo. As primeiras sociedades de ajuda mútua nasceram também sob a influência das experiências associativas anteriores e contemporâneas a elas, tais como as irmandades, as confrarias, os montes de piedade, as casas de misericórdia e as corporações de ofício. Em cada país, as sociedades de socorros mútuos surgiram e se desenvolveram integradas a uma estrutura de instituições relacionadas à previdência, que incluía as seguradoras, os seguros sociais do Estado, as caixas econômicas (montepios ou poupanças) e as cooperativas de compra, venda, produção, construção e crédito.

Paulatinamente, na Inglaterra e nos Estados Unidos consolidou-se o livre associativismo, baseado na formação de sociedades autônomas, voltadas para a assistência, previdência e cooperação entre os trabalhadores, em que a intervenção do Estado era praticamente nula. Em França, Bélgica, Itália, Portugal e Espanha, o livre associativismo conviveu com intervenções do Estado no domínio legislativo, com a execução de programas sociais e com o eventual apoio material do governo. Na Alemanha, a partir da simbiose entre o Estado e a iniciativa 
privada em matéria de previdência, surgiu precocemente a preocupação com o seguro social obrigatório (LIMA, 1909, p. 151).

Em linhas gerais, as associações de ajuda mútua organizavam-se em torno de quatro princípios fundamentais: liberdade, democracia, independência e solidariedade (ROSENDO, 1996, p. 29; QUELHAS, 1999, p. 27). Na prática, isso significava que cada indivíduo, de acordo com sua vontade ou necessidade, tinha a liberdade de filiar-se ou retirar-se da associação a qualquer momento; que as decisões relativas à sociedade seriam deliberadas considerando cada associado um voto, com representação direta e maioria simples; que cada associação possuía autonomia e identidade prlópria diante de outras formas de associação de qualquer natureza, mesmo que se formassem federações ou confederações mutualistas; e, finalmente, que os socorros mútuos seriam sempre uma atividade sem fins lucrativos, visando apenas e, sobretudo, o bem estar do próximo em comunidade.

O mutualismo tornou-se assim um dos elementos fundamentais da "cultura associativa" dos trabalhadores entre a segunda metade do século XIX e o início do século XX. Cultura associativa entendida como o conjunto das práticas concernentes ao "hábito de associar-se" e de "conferir certa institucionalidade a formas de sociabilidade diversas" difundidas entre as classes trabalhadoras. Que diz respeito à produção propriamente cultural das associações: manifestos, estatutos, panfletos, jornais, flâmulas, brasões, pinturas, fotos, estandartes, edificações. Mas inclui também os rituais, os costumes e as normas cotidianas não formuladas que regem o comportamento dos trabalhadores associados e que materializam importantes instrumentos pelos quais estes apreendem o mundo e a si mesmos coletivamente. Ou seja, é o resultado da expressão dos valores e símbolos compartilhados que representam a visão de mundo dos trabalhadores, evidenciados em propostas e práticas culturais diversas, produzidos e difundidos nos discursos e rituais que regem a vida associativa. São práticas e valores eventualmente herdados de organizações mais antigas e que interagem constantemente com a "cultura política" e a "cultura militante" que lhes são contemporâneas, e que constituem elementos essenciais do processo histórico de formação da classe trabalhadora (BATALHA, 2004, p. 96-97, 99).

\section{Portugal e Brasil}

Ainda que pese imenso o fato de que o Brasil era, até o final do século XIX, um país escravista, esse quadro geral permite a análise comparada 
do mutualismo em Portugal e Brasil, partindo-se do pressuposto que havia alguma similaridade entre a estrutura geral das duas sociedades na segunda metade do século XIX e nas primeiras décadas do século XX. Eram ambos os países de economia predominantemente agrária, que passavam naquele momento por um processo tardio de industrialização, em que a indústria nascia grande mas convivia com a manufatura e o artesanato. Além disso, permaneciam dentro de uma certa tradição latina de relação entre a sociedade civil e o Estado e vivenciaram a crise política de suas monarquias constitucionais.

Nos dois países, as décadas de 1820 e 1830 delimitaram o advento do movimento mutualista após a extinção das corporações de ofício. Os anos de 1870 demarcaram, em Portugal, o fortalecimento e a ampliação do fenômeno associativo, decorrentes dos efeitos da Comuna de Paris sobre o movimento social e político dos trabalhadores urbanos (Ver: OLIVEIRA, 1973; MÓNICA, 1985, 1987; ROSENDO, 1996). No Brasil, na mesma década, o associativismo desenvolveu-se amplamente, sob a influência da legislação reguladora de 1860, no contexto de modernização econômica e abolição gradual da escravidão. Também nos dois países, observa-se na década de 1920 a retração das associações de socorros mútuos em meio ao fortalecimento do sindicalismo e às primeiras intervenções do Estado no campo da seguridade social e da previdência (Ver: JESUS, 2006, 2007, 2010; VISCARDI, JESUS, 2007).

Foi, portanto, no período entre 1875 e 1914 que o fenômeno associativo mutualista atingiu seu auge, tanto no Brasil como em Portugal, transformando-se em uma das principais expressões da cultura associativa das classes trabalhadoras urbanas, ao lado dos partidos políticos e dos sindicatos. Há que se considerar que o período entre 1875 e 1914 é definido por pesquisadores dos mais variados matizes como sendo um período homogêneo, principalmente do ponto de vista das estruturas socioeconômicas (Ver: POLANYI, 1944; FIELDHOUSE, 1967; MAYER, 1981; HOBSBAWM, 1987; SAID, 1994; ARRIGHI, 1994. DAVIS, 2001; HARVEY, 2010; PIKETTY, 2014).

Ainda que pese o fato de Portugal e Brasil ocuparem posições diferentes dentro do universo de expansão do capitalismo na era dos impérios, é possível afirmar que havia um movimento único, especialmente na economia dos países ocidentais, que apontava para a recuperação econômica na década de 1870 e uma expansão industrial e modernizadora crescente até 1914. E esse foi o pano de fundo do auge da experiência mutualista. 
Para o caso do Brasil, embora seja difícil delinear o período entre 1875 e 1914 como absolutamente homogêneo, sobretudo em função da abolição da escravidão e da proclamação da República, tem-se firmado na historiografia a tendência a considerar uma certa homogeneidade relativa ao processo de modernização conservadora (Ver: BOSI, 1992, p. 194-245; CARVALHO, 1998, p. 107-129.). Outro elemento de diferenciação significativo entre Portugal e Brasil, além da escravidão, é o fato de que a Belle Époque delimitou um período de hegemonia da cultura e dos valores burgueses nos países mais desenvolvidos do capitalismo ocidental. Obviamente, não se pode falar em hegemonia cultural da burguesia no Brasil. Havia tão somente hegemonia política da oligarquia agrário-exportadora do Sudeste, cuja expressão mais acabada era a defesa de seus interesses econômicos junto aos aparelhos burocráticos e administrativos do Estado (Ver: CARVALHO, 1998, p. 130-154; VISCARDI, 2001).

Entretanto, é o pressuposto de que havia na História elementos que permitem e propiciam a comparação dos casos de Portugal e Brasil, relativos ao fenômeno associativo mutualista entre a segunda metade do século XIX e o início do século XX, que induz à tentativa de se fazer aqui uma análise comparada da historiografia.

\section{Zona de convergência: movimento operário e mutualismo}

Em primeiro lugar, pode-se destacar uma enorme área de convergência entre as tradições historiográficas lusa e brasileira ao longo das décadas de 1950, 1960 e 1970 relativa ao vasto campo da História Social. Em ambos os casos, um conjunto muito amplo de historiadores, voltado para a análise do movimento operário e sindical, logrou equacionar a história das associações de socorros mútuos dentro do debate historiográfico acadêmico.

Entre os brasileiros, as primeiras alusões ao mutualismo remetem às dificuldades de organização dos operários no seio da sociedade escravista (MORAES FILHO, 1952, p. 182). E demarcam a precária capacidade da ação sindical para interferir na fixação da regulamentação do mercado de trabalho (VIANNA, 1978, p. 78.). Além do caráter incipiente e quase sempre ineficiente do mutualismo, nos quadros da ação operária no século XIX, aos socorros mútuos atribui-se o papel de organização do tipo humanitária, incapaz de contribuir para a superação do capitalismo, ou até mesmo destinada a contribuir indiretamente para a perpetuação do mesmo, na medida em que atenua as agruras dos trabalhadores 
tornando a vida mais suportável dentro do sistema (SIMÃO, 1981, p. 151; RODRIGUES, 1968; CARONE, 1979, p. 33; LOBO, STOTZ, 1985, p. 70). Assim sendo, o período entre 1875 e 1914 no Brasil é caracterizado com base na ideia de processo histórico de "evolução", em que se passaria paulatinamente das formas de organização difusas e "moleculares", próprias da sociedade monárquica escravista, para o movimento operário e sindical mais estruturado e combativo típico da Primeira República (LOBO, STOTZ, 1985, p. 65-67).

Pode-se visualizar esse mesmo sentido de evolução nas análises feitas pelos historiadores portugueses preocupados com o movimento operário e sindical. Em linhas gerais o mutualismo do século XIX aparece caracterizado como um dos movimentos precursores daquilo que viria a ser a expressão política da luta de classes no século $\mathrm{XX}$ (Ver: SOUSA, 1972; COSTA, 1979; NUNES et alli, 2011). O resultado em geral é a apresentação do associativismo mutualista como componente da etapa inicial de organização do movimento operário. Etapa dentro da qual se difundia a "ilusão" política da conciliação de classes através da ajuda mútua, que somente depois dos anos de 1870 adquiriria lentamente uma feição socialista e combativa (OLIVEIRA, 1973, p. 133; COSTA, 1975, p. 33-35; RUIVO, LEITÃO, 1977, p. 17; MASCARENHAS, SILVA, 1988, p. 23). Mesmo assim, embora possuísse inicialmente uma "função positiva" na "aurora do movimento operário", o mutualismo seguiria seu caminho no século XX marcado pela ambiguidade e pelo reformismo político (FONSECA, 1978, p. 27).

Trata-se de uma vertente interpretativa que está, ao longo de pelo menos três décadas, preocupada em delimitar com precisão os processos de luta, resistência, reivindicação e organização institucional dos trabalhadores, entendidos como movimentos no sentido da formação da consciência de classe revolucionária. Para tanto, os autores procuram traçar com precisão o quadro geral, em cada país, do advento e da evolução da influência das ideologias políticas de esquerda - socialista, anarquista e comunista - dentro do movimento operário e sindical. A adesão, que em vários casos fazem, direta ou indiretamente, às categorias "luta de classes" e "consciência revolucionária", consideradas muitas vezes hoje em dia ultrapassadas, não pode obscurecer a magnitude da contribuição que os historiadores do movimento operário e sindical oferecem ao estudo do mutualismo.

O caráter engajado e o tom combativo, típico dos autores que escreveram entre os anos de 1950 e 1980, não devem interferir no reconhecimento da qualidade do trabalho de prospecção, da enorme 
capacidade de identificação e classificação das instituições e lideranças ideológicas no contexto do associativismo e do esforço no sentido de produzir cronologias que sintetizam os movimentos sociais e políticos (Ver: RODRIGUES, 1968; RODRIGUES, 1977; VIANNA, 1978; CARONE, 1979; FONSECA, 1980; RODRIGUES, 1980; FONSECA, 1981; SIMÃO, 1981; FONSECA, 1982; FREIRE, 1992). Trata-se de uma fortuna crítica que não se pode menosprezar com base apenas na avaliação negativa dos pressupostos teóricos ou político-ideológicos dos historiadores.

\section{Autores portugueses entre o século XIX e o século XX}

Diferentemente do Brasil, há em Portugal uma produção bibliográfica que antecede em muito os autores acima referidos. São ensaios sociológicos, políticos e filosóficos que analisam o mutualismo desde o momento de sua fundação, em geral produzidos por militantes envolvidos na edificação das associações. Essa tradição inicia-se com os patronos do mutualismo e congrega dezenas de autores e propagandistas tais como Francisco Maria de Sousa Brandão, António Pedro Lopes de Mendonça, Francisco Vieira da Silva Júnior, J. M. da Silva Albuquerque, Joaquim Henriques Fradesso da Silveira, Joaquim Teófilo Fernandes Braga, Eudóxio César Azedo Gneco, Giuseppe Silo Domenico Fontana, Francisco da Silveira, Esteves Pereira, Fernando Maria de Almeida Pedroso, Castelo Branco Saraiva. Entre estes, talvez o mais importante e conhecido seja José Cypriano da Costa Goodolphim (1876, 1889), cuja obra é referência obrigatória nos estudos sobre mutualismo até hoje.

A tendência geral dessa vertente de análise do mutualismo, e do movimento operário como um todo, é o esforço no sentido de delimitar a importância da chamada "questão social" na segunda metade do século XIX e de conferir legitimidade ao empenho dos trabalhadores envolvidos na defesa de seus interesses a partir da organização institucional (GONÇALVES, 1905, p. 36/52; LIMA, 1905, p. 01.). Prevalece também, embora com imensa dificuldade, uma enorme preocupação em caracterizar o mutualismo como sendo uma forma de organização coletiva essencialmente neutra, impermeável ao movimento das ideologias e dos interesses políticos partidários. Isso se faz com base na ideia de que o mutualismo é o resultado da manifestação do "espírito de previdência" inerente aos seres humanos em qualquer período da História (FONSECA, 1887; PEREIRA, 1900; LIMA, 1909, LIMA, 1910; GRILLO, 1912). 
Para além da militância, do fomento e do envolvimento na organização das associações, o grande legado desses escritores é ter coligidos os dados disponíveis sobre o mutualismo, existente até a década de 1910, e oferecer para as gerações futuras um quadro estatístico e institucional detalhado sobre os socorros mútuos em Portugal (Ver: CONGRESSO DAS ASSOCIAÇÕES PORTUGUESAS, 1883, 1884; CONGRESSO NACIONAL DE MUTUALIDADE, 1910).

Mais adiante, na década de 1930, observa-se uma retomada vigorosa da reflexão teórica e da ação prática voltada para o mutualismo, em meio ao processo de consolidação do Estado Novo português. Nesse contexto, um conjunto de autores envolvidos com os ideais do corporativismo e com a militância católica, alinhados à construção do regime autoritário, trazem para o debate político as questões relativas a seguridade social e a previdência observadas do ponto de vista histórico (Ver: ANSELMO, 1933; COSTA JUNIOR, 1937; COSTA, 1933; CUNHA, 1933; SANTOS, 1941; SOUSA, 1933).

Em linhas gerais, os intelectuais ligados ao novo regime defendem a expansão dos "sindicatos nacionais" e dos "grêmios e casas do povo" (ANSELMO, 1934, p. 19), cujo sentido último seria implantar o mutualismo obrigatório entendido como instituição corporativa que envolveria creches, escolas, hospitais, asilos e sociedades de classes (SANTOS, 1933, p. 05). Avaliam que o único caminho para se evitar a suposta crise de estagnação, que afetava as associações de socorros mútuos nos anos 1930, seria a incorporação destas às novas diretrizes do Estado (ANSELMO, 1938, p. 36.), amparadas nos ideais de bemestar social, altruísmo, fraternidade e cristianismo (GOMES, 1933, p. 48; BASTOS, 1938, p. 23; PEREIRA, s.d., p. 06.).

Há também em Portugal uma vertente de trabalhos produzidos no seio das próprias associações, em geral, de caráter comemorativo ou como registro da expressão local do associativismo mutualista. No Brasil esse tipo de produção é praticamente inexistente, em função da diminuição brutal do número de associações em funcionamento no século XX. Em Portugal, com cerca de uma centena de sociedades de socorros mútuos hoje em dia em funcionamento, há ainda grande espaço para a divulgação de uma bibliografia institucional das associações (Ver: FONSECA, 1887; AMZALAK, 1923; SANTOS, 1932; SANTOS, 1933; SANTOS, 1939; BRETES, 1962; COELHO, 1973; OLIVEIRA, 1973; FERREIRA, 1978; SANTOS, 1983; SILVEIRA, 1986; MARTINS, 1991; RAMOS, 1991; LUNET, 1996; MALHEIRO, 1996; MARQUES, 1997; TARRACHA, 1997; CARVALHO, 1998; 
CORREIA, 2000; MARTINS, 2000; TAVARES, 2001; NUNES, 2004). Por fim, em Portugal delineia-se ainda um vasto campo de investigação das associações de ajuda mútua erigidas por emigrantes portugueses em outros países (Ver: MELO, SILVA, 2009).

\section{Mutualismo e a formação das classes trabalhadoras no Brasil}

A produção historiográfica voltada para o estudo das classes trabalhadoras, do movimento operário e dos partidos e sindicatos de esquerda no Brasil sofreu um amplo processo de remodelação dos marcos teórico-metodológicos da pesquisa a partir do final da década de 1980. Sob influência direta da produção intelectual dos chamados marxistas britânicos, entre outros autores (Ver: THOMPSON, 1966; PERROT, 1973; SAMUEL, 1975; GUTMAN, 1977; TILLY, SCOTT, 1978; HANAGAN, 1980; SEWELL JR., 1980, HOBSBAWM, 1984), pode-se dizer que se consolidou de modo quase hegemônico o paradigma que postula a concepção da classe trabalhadora como fenômeno essencialmente cultural e histórico (JESUS, MALERBA, 2016, p. 154-156). Esse redimensionamento da pesquisa em História Social do Trabalho conduz, automaticamente, à análise dos processos de construção dos laços de solidariedade vertical e horizontal, das rivalidades, consensos, negociações e das tradições na formação das identidades profissionais, étnicas, de gênero e de classe.

Dentro deste espectro, o interesse pelas sociedades de socorros mútuos se vê renovado entre os historiadores brasileiros a partir do final dos anos de 1980.

Tânia Regina de Luca (1980), em pesquisa pioneira, evidencia o crescimento do mutualismo - entre os trabalhadores urbanos desde o final do século XIX até meados da década de 1920 -, como forma de resistência a exploração e como resposta a ausência de mecanismos institucionais que regulassem a relação capital-trabalho. Beatriz Kushnir (1996), ao estudar as associações de ajuda mútua que reuniam prostitutas e cafetinas judias, desvenda os mecanismos de sociabilidade e solidariedade desenvolvidos pelas polacas e consegue captar as "visões do grupo sobre si" - enquanto segmento marginal dentro da comunidade judaica e da sociedade como um todo -, em luta constante pelo direito de exercer suas convicções religiosas e explorando suas associações como referência na construção de uma "vida digna" e na separação entre o tempo de trabalho e de lazer. 
Adhemar Lourenço da Silva Jr. (2004) analisa a relação das associações mutuais com as elites econômicas, os potentados locais e o Estado, identificando o movimento de troca de benefícios e proteção por apoio político. Prioriza a abordagem da regulamentação das associações de socorro mútuo pelo Estado brasileiro - desde as primeiras incursões da Monarquia até as mudanças formais introduzidas com advento da República - com destaque para a ação do Estado rumo à criação de um mercado previdenciário nacional, que levaria ao esvaziamento das mutuais nas décadas de 1930 e 1940. Cláudia Viscardi (2004, 2006, 2008) procura ressaltar que a experiência mutualista resultou de escolhas estratégicas de diferentes atores sociais, na busca dos mais diversificados interesses de ascensão social - ou prevenção contra o descenso - que não excluíam, por sua vez, a utilização de estratégias complementares e coetâneas, tais como a militância sindical ou a prática e/ou o usufruto da filantropia.

Sidney Chalhoub (2007), ao se dedicar à análise das sociedades que agregavam ex-escravos e "homens de cor" no Rio de Janeiro imperial, permite que se vislumbre o fenômeno associativo entendido como resultado das práticas de solidariedades horizontais observáveis em meio aos mecanismos de dominação política e cultural típicos do paternalismo escravista. Vitor Fonseca (2008) investiga as normas legais que orientavam o associativismo no Rio de Janeiro no início do século XX, entendido como personalidade jurídica cujo objetivo é a ampliação da cidadania, enquanto agente político mediador do diálogo entre sociedade civil e Estado.

Tomando-se em conta os trabalhos acadêmicos mais importantes, pode-se afirmar com segurança que é a partir da obra de Cláudio Batalha que os fenômenos do associativismo e do mutualismo ganham contornos definitivos na recente historiografia brasileira. No volume especial da Coleção Cadernos do AEL (1999), dedicado ao estudo das sociedades operárias, Batalha ressalta a necessidade de se romper com a visão tradicional que separa a ocorrência das associações mutualistas e sindicais em etapas distintas que se sucediam na história do Brasil, e contesta a ideia de que as associações de resistência teriam substituído as mutuais. Neste sentido, demarca que as ações de ambos os tipos de associação de trabalhadores se confundiram durante um período de tempo. Ou seja, as mutuais incorporavam ações de resistência e os sindicatos promoviam ações assistencialistas. Há também em sua análise atenção explícita aos elos de continuidade entre as sociedades de socorros mútuos e as corporações de ofício. Supõe que a proibição 
das corporações (1824) teria levado à proliferação das mutuais que abrigariam, a partir de então, a tarefa de transmissão de conhecimentos relativos aos ofícios. Para além disso, as sociedades de ajuda mútua incorporariam também ações de resistência, o que, de certa forma, anteciparia funções próprias das associações sindicais. Assim, as mutuais teriam sido os únicos mecanismos legalmente possíveis de agregação dos trabalhadores entre o final do século XIX e início do XX, sem o qual dificilmente o movimento sindical teria se desenvolvido.

Posteriormente, Cláudio Batalha (2004) volta-se para a análise da cultura própria dos diferentes tipos de associações de trabalhadores, partindo da distinção básica entre "cultura militante", "cultura associativa" e "cultura de classe". Destaca que a década de 1920 teria sido palco do advento de uma cultura operária, em grande parte fruto do desdobramento da cultura militante anarquista, paradoxalmente no momento em que o movimento operário encontrava-se em refluxo, impedindo assim o advento de uma cultura de classe consolidada entre os trabalhadores. Além disso, reafirma a importância dos rituais e celebrações dos trabalhadores, principalmente em torno das comemorações do Primeiro de Maio que, nas décadas anteriores a 1890, permaneciam a cargo das sociedades mutualistas.

Com efeito, ao longo dos últimos quinze anos, a partir do Centro de Pesquisa em História Social da Cultura (CECULT-UNICAMP), Cláudio Batalha logrou agregar um grupo relativamente coeso de historiadores que têm estabelecido o "estado da arte" no que se refere ao mutualismo no Brasil. Em 2010, apresenta um balanço da produção historiográfica e, por meio da crítica minuciosa da produção que se acumula desde os anos de 1990, redefine os parâmetros para evolução das pesquisas dentro do campo. Em 2014, juntamente com Marcelo Mac Cord, coordena uma coletânea que congrega trabalhos dos principais historiadores brasileiros envolvidos com o associativismo e o mutualismo. Entre estes estão Aldrin Castellucci (2015), Artur Vitorino (2000), Claudia Viscardi (2009), David Lacerda (2011), Marcelo Mac Cord (2012), Mônica Martins (2008), Oswaldo Maciel (2011), Paula Nomelini (2007) e Rafaela Leuchtenberger (2007).

\section{O estudo do mutualismo em Portugal após o "25 de Abril"}

A reflexão acadêmica sobre o associativismo conheceu um impulso decisivo sob os efeitos da Revolução de 1974, em meio ao renovado interesse pelas associações profissionais, sindicatos, associações de 
moradores, associações culturais, recreativas e desportivas, em função do reconhecimento da importância destas para o processo de reconstrução da sociedade portuguesa pós-revolução. Entretanto, em comparação com o Brasil, a reflexão histórica sobre o associativismo mutualista encontra-se em Portugal, nas últimas três décadas, completamente diluída entre os domínios das Ciências Sociais.

Nesse contexto, os trabalhos abordam principalmente aspectos quantitativos que envolvem a formação dos grupos sociais organizados em associações, assim como a evolução dos arranjos institucionais das entidades (Ver: LOPES, 1995; BARROS, SANTOS, 1998; PITACAS, 2009; MAÇARICO, 2010; SARAIVA, 2011.). Via de regra, apresentam referências importantes sobre as raízes históricas do movimento associativo na atualidade, e também do associativismo mutualista.

Entre os vários autores mais ligados à área da Sociologia (Ver: RAMOS, 1991; VILAÇA, 1993; MELO, REIS, 1998; HENRIQUES, 1999; QUELHAS, 1999; SILVA, 2002; SOARES, 2003; BRÁS, 2004; FREIRE, 2004; MONTEIRO, 2004; VENTURA, 2006; CARDOSO, ROCHA, 2009; SANTOS, 2012; BENTO, 2013.), Maria Alexandre Lousada, por exemplo, analisa o processo de estruturação jurídica e de constituição do peso político institucional das associações profissionais, a partir da apresentação de um panorama histórico que se inicia no final do século XVIII, marcado pela defesa e construção do prestígio dos ofícios, do mercado profissional e da cooperação de classe. E ressalta que, particularmente entre a segunda metade do século XIX e as primeiras décadas do século $\mathrm{XX}$ - mais precisamente, entre os finais do Antigo Regime e o advento do Estatuto do Trabalho Nacional -, foram criadas em Portugal mais de três mil associações (beneficentes, cívicas, de classe, patronais, de socorro mútuo e de cultura e recreio). Portanto, os dados estatísticos revelam, de forma contundente, o vigor do fenômeno associativo entre os portugueses no período que vai de 1834 a 1974 (LOUSADA, 2004, p. 31).

Entre os historiadores, destacam-se os trabalhos de César Oliveira (1973), em que o associativismo e os socorros mútuos são apresentados como veículos para a gradual difusão do socialismo, marcados pela conjuntura estabelecida a partir da Comuna de Paris. E de Maria Filomena Mónica $(1985,1986,1987)$, cuja obra aponta constantemente para a importância do associativismo e do mutualismo na história formação das classes trabalhadoras em Portugal, especialmente na segunda metade do século XIX. 
Certamente, o grande destaque das últimas três décadas é o trabalho de Vasco Rosendo (1996), onde se encontra uma minuciosa descrição do mutualismo em Portugal, desde os seus primórdios, com atenção especial aos processos de formação, às variações de modalidade e às distinções jurídicas entre as instituições. Além disso, a dimensão avultada dos dados coligidos permite acompanhar o desenvolvimento histórico das associações desde a segunda metade do século XIX até o final do século XX.

\section{Perspectivas e desafios da historiografia}

A análise comparada dos processos históricos e da historiografia do Brasil e de Portugal, no que tange à história da cultura associativa, advém da observação da aproximação efetiva que a produção histórica dos dois países vivenciou nos últimos quinze anos.

Foi a partir dos eventos comemorativos das grandes efemérides do final do século XX - "descobrimento da América" e "500 anos da colonização do Brasil" -, que os ambientes acadêmicos, português e brasileiro, iniciaram um intercâmbio intelectual consistente, crescente e contínuo na área de História. Sem dúvida, a investigação histórica dos processos de colonização, povoamento, exploração e administração da América portuguesa, especialmente para o período que abarca a construção do império ultramarino, constituiu o eixo principal que alavancou a interação entre os principais programas de pós-graduação e centros de excelência em pesquisa situados em São Paulo, Rio de Janeiro e Lisboa.

No entanto, esse movimento intelectual e institucional não se restringiu tão somente aos temas da colonização, nem tampouco permaneceu restrito aos principais centros de reflexão acadêmica. Há um movimento de ampliação constante do espectro das pesquisas que reúnem objetos históricos comuns aos dois países, em que os trabalhos voltados para a investigação do processo de formação da classe e da cultura dos trabalhadores, no Brasil e em Portugal, se afiguram como indícios da expansão dos horizontes analíticos e empíricos em que se apoiam os respectivos campos acadêmicos.

Embora não seja, nem de longe, um dos principais objetos de investigação, entre portugueses e brasileiros, o estudo histórico do mutualismo na era dos impérios ocupa seguramente um espaço relevante inserido no debate relativo à formação das classes trabalhadoras dos dois países no período. 
No Brasil, a história do mutualismo surge tardiamente no século XX como um desdobramento necessário da historiografia acadêmica do movimento operário de esquerda. Mais que isso, representa, a partir dos anos de 1980, um esforço analítico cujo objetivo é aprimorar o entendimento sobre o processo de formação das classes trabalhadoras para além dos marcos institucionais e formais ideológicos. Nesse sentido, trata-se de uma produção historiográfica que nasce situada dentro do campo restrito da História do Movimento Operário e que verticaliza sua abordagem em direção a uma História Social da Cultura das classes trabalhadoras.

No Brasil o impacto da obra de E. P. Thompson é fundamental. Portanto, pode-se dizer que o estudo do mutualismo representa a análise histórica de um dos elementos da experiência das classes trabalhadoras em formação, na virada do século XIX para o século XX. Ou seja, o mutualismo é comumente visto como uma das formas culturais pelas quais os trabalhadores interpretaram sua experiência coletiva. Uma das formas de consciência coletiva relativas à experiência de grupos de trabalhadores urbanos, em um momento histórico que antecede a emergência de "uma" classe trabalhadora (no sentido thompsoniano do termo).

Em Portugal o mutualismo foi estudado, ao longo de um século e meio, majoritariamente a partir de uma perspectiva que privilegia a história da organização institucional das associações, juntamente com a percepção do impacto econômico e da variação dos dados estatísticos relativos ao tamanho das organizações e ao número de associados. Há, portanto, uma preocupação reiterada em dimensionar a experiência mutualista no contexto geral da sociedade, observando seus efeitos sobre a dinâmica social e seu impacto sobre a economia, tanto da perspectiva dos associados como dos agentes macroeconômicos. Ou seja, a produção historiográfica portuguesa sobre o mutualismo encontra-se em contato constante com os domínios da Economia e da Sociologia, principalmente, permanecendo ao longo do tempo como uma espécie de subcampo de uma História Social mais tradicional.

Em Portugal, os sinais de uma aproximação teórico-metodológica ao marxismo britânico são bem menos evidentes se comparados ao Brasil, com destaque para a obra de Maria Filomena Mónica e o artigo pioneiro, embora não declaradamente thompsoniano, em que José Pacheco Pereira (1982) discute a importância do mutualismo no processo de formação da classe trabalhadora portuguesa. Quando se observa a produção historiográfica mais específica sobre o mutualismo, 
não há indícios de uma adesão aguda às reflexões teórico-metodológicas de Thompson. Pelo menos não tão aguda quanto a que houve no Brasil a partir dos anos de 1980 .

Esse quadro geral permite que se vislumbre os desafios que se colocam para que o estudo do mutualismo avance como campo particular de pesquisa histórica em Portugal e no Brasil, tendo em vista as possibilidades de influência mútua das duas tradições historiográficas.

Seria extremamente frutífero, por exemplo, se em Portugal o mutualismo fosse mais exaustivamente estudado do ponto de vista thompsoniano, amplamente difundido no Brasil. Ou seja, analisado como parte do conjunto das experiências comuns às classes trabalhadoras. Experiências herdadas ou partilhadas, tratadas em termos culturais pelas consciências coletivas de grupos restritos de trabalhadores urbanos, e encarnadas em tradições, sistemas de valores, ideias e formas institucionais, típicas do processo de formação da classe trabalhadora, principalmente no período entre 1875 e 1914.

Por sua vez, o olhar dos historiadores do mutualismo no Brasil poderia ampliar-se no sentido de equacionar o associativismo mutualista dentro dos marcos mais amplos da economia e da sociedade em que está inserido. Isso contribuiria para superar uma certa estagnação aparente, pois, se as formulações de Thompson foram capazes de produzir uma espécie de ampla revisão historiográfica há trinta anos atrás - que entre outras coisas possibilitou o avanço dos estudos sobre mutualismo no Brasil -, hoje em dia aparecem mais como um pressuposto comum a todos os historiadores da História Social do Trabalho, incapaz de inspirar o surgimento de novos objetos e hipóteses de pesquisa.

\section{Referências}

AMZALAK, Moses Bensabat. O mutualismo e o cooperativismo na indústria da pesca de bacalhau; Comunicação feita ao Congresso da Pesca do Bacalhau reunido em Aveiro em 8 e 9 de outubro de 1923 e promovido pela Associação da Classe dos Armadores de Navios de Portugal. Lisboa: Tipografia da Empresa Diário de Notícias, 1923.

ANSELMO, Manuel. O mutualismo como doutrina social; Conferência promovida a 21 de janeiro de 1933 em Viana-do-Castelo, na Associação Marítima, e repetida depois, em Monção, no Teatro Cine, a convite da Associação de Socorros Mútuos "A Artística Monçanense". Viana do Castelo: Tipografia Comercial A Aurora do Lima, 1933.

. As ideias sociais e filosóficas do Estado Novo; Conferência proferida em Lisboa, no Teatro de São Carlos, a 23 de janeiro de 1934, sob a presidência de Sua Excelência, o Sr. Ministro do Interior, Capitão Raul Gomes Pereira. Porto: Livraria Tavares Martins, 1934. 
. O mutualismo como doutrina social; esboço filosófico. Abertura de Antero Figueiredo. 2. ed. Porto: Livraria Civilização, 1938.

ARRIGHI, Giovanni. The Long Twentieth Century; money, power, and the origins of our times. London; New York: Verso, 1994.

BARROS, Carlos Pestana; SANTOS, J. C. Gomes (Orgs.). O Mutualismo Português; solidariedade e progresso social. Lisboa: Vulgata, 1998.

BASTOS, A. de Magalhães. Origens e tradições do mutualismo português e em especial do Portuense; separata do "Boletim Cultural" da Câmara Municipal do Porto, v. I, fac. I. Porto: Tipografia Leitão, mar. 1938.

BATALHA, Cláudio H. M. Sociedades de Trabalhadores no Rio de Janeiro do século XIX: algumas reflexões em torno da formação da classe operária. Cadernos AEL: sociedades operárias e mutualismo, Campinas: IFCH/Unicamp, v. 6, n. 10/11, p. 41-68, 1999.

- Relançando o debate sobre o mutualismo no Brasil: as relações entre corporações, irmandades, sociedades mutualistas de trabalhadores e sindicatos à luz da produção recente. Revista Mundos do Trabalho, v. 2, n. 4, p. 12-22, ago.-dez. 2010.

BATALHA, Cláudio H. M.; SILVA, Fernando Teixeira da; FORTES, Alexandre (Orgs.). Culturas de classe: identidade e diversidade na formação do operariado. Campinas, São Paulo: Editora da UNICAMP, 2004.

BENTO, Miguel da Conceição. Vida e morte numa mina do Alentejo; pobreza, mutualismo e provisão social; o caso de S. Domingo (Mértola) na primeira metade do século XX. Castro Verde: 100 Luz, 2013.

BOSI, Alfredo. A escravidão entre dois liberalismos. In: Dialética da colonização. São Paulo: Companhia das Letras, 1992. p. 194-245.

BRÁS, Rui Manuel. Formas institucionais e sistema de valores; as associações de sapateiros de Lisboa da segunda metade do século XIX ao Estado Novo. Oeiras: Celta Editora, 2004.

BRETES, Faustino. Centenário do mutualismo em Torres Novas. Coimbra: Coimbra Editora, 1962.

CARDOSO, José Luís; ROCHA, Maria Manuela. O seguro social obrigatório em Portugal (1919-1928); acção e limites de um Estado previdente. Análise Social, v. XLIV, n. 192, p. 439-470, 2009.

CARONE, Edgar. Movimento operário no Brasil (1877-1944). São Paulo: Difel, 1979.

CARVALHO, Domingos. Mutualismo; a força do associativismo democrático. Lisboa: Ciência Gráfica, 1998. (Cadernos CA-3).

CARVALHO, José Murilo de. Brasil 1870-1914: a força da tradição. In: Pontos e bordados: escritos de história e política. Belo Horizonte: Editora da UFMG, 1998. p. 107-129.

. Mandonismo, coronelismo, clientelismo: uma discussão conceitual. In: Pontos e bordados: escritos de história e política. Belo Horizonte: Editora da UFMG, 1998. p. 130-154.

ELLUCCI, Aldrin A. S. Trabalhadores e política no Brasil; do aprendizado do Império aos sucessos da Primeira República. Salvador: Editora da Universidade do Estado da Bahia, 2015. 
CEDEÑO, Reynaldo Sordo. Las sociedades de socorros mutuos, 1867-1880. Historia Mexicana, v. 33, n. 1, p. 72-96, jul.-sept. 1983.

CHALHOUB, Sidney. Solidariedade e liberdade; sociedades beneficentes de negros e negras no Rio de Janeiro na segunda metade do século XIX. In: CUNHA, Olívia Maria Gomes da; GOMES, Flávio dos Santos (Orgs.). Quase-cidadão; histórias e antropologias da pós-emancipação. Rio de Janeiro: Editora FGV, 2007. p. 219-240.

COELHO, Elmano de Lage Simões. Cem anos depois (1872-1972); publicação comemorativa do Centenário de Associações de Socorros Mútuos de Empregados no Comércio de Lisboa. Lisboa: Associação de Socorros Mútuos dos Empregados no Comércio de Lisboa, 1973.

CONGRESSO DAS ASSOCIAÇÕES PORTUGUESAS; Junta do Departamento Sul. Primeiro Congresso das Associações Portuguesas realizado na Câmara Municipal de Lisboa; Desde 10 a 18 de junho de 1882. Lisboa: Tipografia Universal, 1883a.

Relatório sobre a Federação dos Serviços Clínicos e Administrativos; apresentado pela respectiva seção na sessão da Junta do Departamento Sul de 2 de julho de 1883. Lisboa: Tipografia Universal, $1883 \mathrm{~b}$.

Primeiro Congresso das Associações Portuguesas realizado na Câmara Municipal de Lisboa; Desde 10 a 15 de junho de 1883; Relatórios das Seções da Junta do Departamento do Sul. Lisboa: Tipografia Universal, 1884.

CONGRESSO NACIONAL DE MUTUALIDADE. Da ação da mutualidade na Federação dos Serviços Farmacêuticos; Liga das Associações das Farmácias. Porto: [s.n.], 1910a.

. Do processo de estruturação, contabilidade e estatística das associações de socorros mútuos; Tese Subsidiária. Porto: [s.n.], $1910 \mathrm{~b}$.

. Justificação dos fatores que obstaram a construção de uma liga associativa em Lisboa para os serviços farmacêuticos - 1906-1910. Lisboa: [s.n.], 1910c. $\overline{1910 \mathrm{~d} .}$

. Subsídios para a reforma do Decreto de 2 de outubro de 1886. Lisboa: [s.n.],

Tese XIV; Da ação da mutualidade na federação dos serviços farmacêuticos; Liga das Associações; Das farmácias. Lisboa: [s.n.], 1910e.

Tese XIV; Da ação da mutualidade na federação de serviços farmacêuticos; Liga das Associações de Farmácias; Das farmácias mutualistas. Porto: [s.n.], $1910 \mathrm{f}$.

CORREIA, Rui Antunes. Uns aos outros; o Montepio Caldense (1860-1890). Rio Maior: Grafiartes, 2000.

COSTA JÚNIOR, José Maria Marques. A organização de classes. Angra do Heroísmo: Tipografia Andrade, 1937.

. História Breve do Movimento Operário Português. Lisboa: Verbo, 1964.

COSTA JÚNIOR, José Maria Marques. Movimento operário português. Lisboa: Verbo, 1964.

COSTA, Ramiro da. O desenvolvimento do capitalismo em Portugal. Lisboa: Assírio \& Alvim, 1975.

. Elementos para a história do movimento operário em Portugal. $1^{\mathrm{O}}$ volume 1820-1929. Lisboa: Assírio \& Alvim, 1979. 
COSTA, Severino. Mutualismo e fraternidade humana; conferência proferida na Associação Fraternal dos Artistas Vianenses durante a Semana do Mutualismo. Viana: Tipografia Comercial "A Autora do Lima”, 1933.

CUNHA, F. Carmo. Manifestações do espirito de previdência; o Mutualismo; Conferência realizada no Montepio Geral no dia 18 de Janeiro de 1933. Lisboa: Instituto Superior de Ciências Económicas e Financeiras, 1933.

DAVIS, Mike. Late Victorian Holocausts; El Nino, famines and the making of the Third World. London; New York: Verso, 2001.

DREYFUS, Michel. Liberté, Égalité, Mutualité. Mutualisme et Syndicalisme, 1852-1967. Paris: Les Éditions de l'Atelier/Éditions Ouvrières, 2001.

FERREIRA, Jaime. Para a história do mutualismo; nas bodas de ouro de "A Previdência”. Porto: Tipografia Marca, 1978.

FIELDHOUSE, David Kenneth. The colonial empires; a comparative survey from the eighteenth century. New York: Delacorte Press, 1967.

FONSECA, Carlos da. A origem da $1^{\text {a }}$ Internacional em Lisboa; o centenário da Federação Portuguesa. Lisboa: Editorial Estampa, 1978.

. História do Movimento Operário e das Idéias Socialistas em Portugal; I-Cronologia. Viseu: Europa-América, 1980.

. História do Movimento Operário e das Idéias Socialistas em Portugal; III - O Operariado e a Igreja militante (Da Rerum Novarum à implantação da República). Viseu: Europa-América, 1981. IV - Greves e

História do Movimento Operário e das Idéias Socialistas em Portugal;

FONSECA, Fernandes da. Número único para comemorar o aniversário do benemérito iniciador das associações mútuas em Portugal. Lisboa: Tipografia do Comércio de Portugal, 1887.

FONSECA, Vitor Manuel Marques da. No gozo dos direitos civis: associativismo no Rio de Janeiro (1903-1915). Rio de Janeiro/Niterói: Arquivo Nacional/Muiraquitã, 2008.

FREIRE, João. Anarquistas e Operários; ideologia, ofício e práticas sociais: o anarquismo e o operariado em Portugal (1900-1940). Porto: Afrontamento, 1992.

(Org.). Associações Profissionais em Portugal. Oeiras: Celta Editora, 2004.

GOMES, Álvaro Reis. Mutualismo; Conferência realizada no salão nobre do Montepio Madeirense em 20 de janeiro de 1933. Funchal: Tipografia Diário da Madeira, 1933.

GONÇALVES, Luiz. A evolução do movimento operário em Portugal. Lisboa: Adolpho de Mendonça \& Cia., 1905.

GOODOLPHIM, José Cypriano da Costa. A Associação: história e desenvolvimento das associações portuguesas. Lisboa: Tipografia Universal, 1876.

. A Previdencia: Associações de Socorros Mútuos, Cooperativas, Caixas de Pensões e Reformas, Caixas Econômicas. Lisboa: Imprensa Nacional, 1889.

GRILLO, J. Francisco. Mutualismo rural e crédito agrícola: primeira tentativa de sua criação em Portugal sem encargos para o Estado, baseada numa Lei que torne obrigatória a mutualidade agrícola. Lisboa: Livraria Ferin Baptista Torres, 1912. 
GUTMAN, H. Work, culture and society industrializing America. New York: Vintage Books, 1977.

HANAGAN, M. P. The logic of solidarity. Chicago: University of Illinois Press, 1980. HARVEY, David. The enigma of capital: and the crises of capitalism. London: Profile Books, 2010.

HENRIQUES, Maria Adosinda. Origens do associativismo na Beira Litoral: da tradição à modernidade. Lisboa: Direção Geral de Desenvolvimento Rural, 1999.

HOBSBAWM, Eric J. Labour History and Ideology. In: Workers: worlds of labor. New York: Pantheon Books, 1984.

HOBSBAWM, Eric J. The Age of Empire, 1875-1914. New York: Pantheon Books, 1987.

JESUS, Ronaldo P. de. História e historiografia do fenômeno associativo no Brasil monárquico. In: ALMEIDA, Carla M. C.; OLIVEIRA, Mônica R. de. Nomes e números: alternativas econômicas para a história econômica e social. Juiz de Fora: Ed. UFJF, 2006.

. Associativismo no Brasil do século XIX: repertório crítico dos registros de sociedades no Conselho de Estado (1860-1889), Locus: Revista de História. v. 13, n. 1, 144-170, 2007.

. Mutualismo entre ex-escravos e operários no Rio de Janeiro. In: LOBO, Valéria Marques; DELGADO, Ignácio Godinho; VISCARDI, Cláudia Maria Ribeiro (Orgs.). Trabalho, proteção e direitos: o Brasil além da Era Vargas. Juiz de Fora: Ed. UFJF, 2010. p. 9-27.

JESUS, Ronaldo P. de; MALERBA, Jurandir. Marxism and Brazilian Historiography. In: WANG, Q Edward; IGGERS, Georg G. Marxist Historiographies: a global perspective. London; New York: Routledge, 2016. p. 142-173.

KUSCHNIR, Beatriz. Baile de máscaras. Mulheres judias e prostituição: as polacas e suas associações de ajuda mútua. Rio de Janeiro: Imago, 1996.

LACERDA, David P. Solidariedade entre oficios; a experiência mutualista no Rio de Janeiro (1860-1882). 2011. Dissertação (Mestrado em História) - Instituto de Filosofia e Ciências Humanas, Universidade de Campinas, Campinas, 2011.

LEUCHTENBERGER, Rafaela. O lábaro protetor da classe operária; as associações voluntarias de socorros-mútuos dos trabalhadores em Florianópolis, Santa Catarina (1886-1932). 2007. Dissertação (Mestrado em História) - Instituto de Filosofia e Ciências Humanas, Universidade de Campinas, Campinas, 2007.

LIMA, João Evangelista Campos. Movimento operário em Portugal. Lisboa: Guimarães \& Cia., 1910.

LIMA, José Lobo D’Avila. Movimento operário em Portugal. Lisboa: Ferreira \& Oliveira, 1905.

. Socorros Mútuos e Seguros Sociais. Coimbra: Imprensa da Universidade, 1909.

LINDEN, Marcel van der. Social Security Mutualism. The Comparative History of Mutual Benefit Societies. Bern: Peter Lang, 1996.

LOBO, Eulália Maria Lehmeyer; STOTZ, Eduardo Navarro. Formação do operariado e movimento operário no Rio de Janeiro, 1870-1894. Estudos Econômicos, São Paulo, v. $15,49-88,1985$. 
LOPES, Raimundo José Ferreira. Sociedade de Instrução e Beneficência: “A Voz do Operário", uma associação representativa da classe dos Manipuladores de Tabaco, em particular, e da classe operária, em geral. 1995. Dissertação (Mestrado em Antropologia Cultural e Social da Cultura) - Faculdade de Ciências Sociais e Humanas da Universidade Nova de Lisboa. Lisboa, 1995.

LOUSADA, Maria Alexandre. Associações profissionais: tradição e renovação. In: FREIRE, João (Org.). Associações Profissionais em Portugal. Oeiras: Celta Editora, 2004. p. 21-55.

LUCA, Tânia R. de. O sonho do futuro assegurado: o mutualismo em São Paulo. São Paulo: Contexto, 1990.

LUNET, Carlos Alberto Homem de Figueiredo. Associativismo e mutualismo: Associação de Socorros Mútuos "19 de Março" (1892-1992). Tondela: Tipografia Tondelgráfica, 1996.

MAC CORD, Marcelo. Artifices da Cidadania: mutualismo, educação e trabalho no Recife oitocentista. Campinas: Editora da Unicamp, 2012.

MAC CORD, Marcelo; BATALHA, Cláudio H. M. (Org.). Organizar e Proteger: trabalhadores, associações e mutualismo no Brasil (séculos XIX e XX). Campinas: Editora da Unicamp, 2014.

MAÇARICO, Luís Filipe. Associativismo, patrimônio e cidadania. [S.1.]: Ciência Gráfica, 2010.

MACIEL, Osvaldo B. A. A Perseverança dos Caixeiros: o mutualismo dos trabalhadores do comércio em Maceió. Recife: EDUFPE, 2011.

MALHEIRO, José. Associativismo popular: originalidade do povo português. Almada: Câmara Municipal de Almada, 1996.

MARQUES, Emília Margarida. A associação "Recurso Operário": antecedentes e alguma contextualização. Marinha Grande: Museu Santos Barbosa da Fabricação do Vidro, 1997.

MARTINS, José António de Jesus. Da Irmandade do Corpo Santo dos mareantes e pescadores da cidade de Lagos à "A Lacobrigense” Associação de Socorros Mútuos (1749-1999). Lagos: A Lacobrigense, 2000.

. História breve da Associação dos Bombeiros Voluntários de Lagos (18861990). Lagos: Associação dos Bombeiros Voluntários, 1991.

MARTINS, Mônica de Souza Nunes. Entre a Cruz e o Capital: as corporações de ofícios após a chegada da família real (1808-1824). Rio de Janeiro: Editora Garamond, 2008.

MASCARENHAS, João Mário; SILVA, João Evaristo. Socialismo em Portugal: os primeiros ecos. Lisboa: Câmara Municipal de Lisboa/Biblioteca Museu da República e Resistência, 1988.

MAYER, Arno J. The persistence of the Old Regime: Europe to the Great War. London: Pantheon Books, 1981.

MELO, Daniel; SILVA, Eduardo Caetano (Orgs.). Construção da Nação e Associativismo na Emigração Portuguesa. Lisboa: ICS. Imprensa de Ciências Sociais, 2009.

MELO, Lilia; REIS, Suzana. Mutualismo na área da Grande Lisboa: principais características e perspectiva de evolução. In: BARROS, Carlos Pestana; SANTOS, J. C. Gomes (Orgs.). O Mutualismo Português: solidariedade e progresso social. Lisboa: Editora Vulgata, 1998. p. 69-99. 
MÓNICA, Maria Filomena. O Movimento Socialista em Portugal (1875-1934). Lisboa: Casa da Moeda / Instituto de Estudos para o Desenvolvimento, 1985.

. Artesãos e operários: indústria, capitalismo e classe operária em Portugal (1870-1934). Lisboa: ICS - Universidade de Lisboa, 1986.

1987.

. Capitalistas e industriais. 1870-1914. Análise Social, v. XXIII, n. 99, p. 819-863,

MONTEIRO, Alcides A. Associativismo e Novos Laços Sociais. Coimbra; Quarteto, 2004.

MORAES FILHO, Evaristo de. O problema do sindicato único no Brasil: seus fundamentos sociológicos. Rio de Janeiro: Editora A Noite, 1952.

MUNCK, Ronaldo. Mutual benefit societies in Argentina; workers, nationality, social security and trade unionism. Journal of Latin American Studies, Cambridge, n. 30, p. 573-590, 1998.

NOMELINI, Paula C. B. Associações operarias mutualistas e recreativas em Campinas (1906-1930). 2007. Dissertação (Mestrado em História) - Instituto de Filosofia e Ciências Humanas, Universidade de Campinas, Campinas, 2007.

NUNES, Américo; CABRITA, Daniel; MARTINS, Emídio; ROCHA, Francisco Canais; CARTAXO, Ernesto; BARRETO, Kalídas; RANITA, Víctor. Contributo para a História do Movimento Operário e Sindical: das raízes até 1977. Lisboa: CGTP-IN - Departamento de Cultura e Tempos Livres / IBJC - Instituto Bento de Jesus Caraça, 2011.

NUNES, Mário. A Previdência Portuguesa; associação mutualista; 75 anos ao serviço do mutualismo - 1929-2004. Coimbra: Carvalho \& Simões, 2004.

OLIVEIRA, César. O Socialismo em Portugal (1850-1900): contribuição para o estudo da filosofia política e do socialismo em Portugal na segunda metade do século XIX. Porto: Afrontamento, 1973.

PEREIRA, João Manuel Esteves. A indústria portuguesa (séculos XII a XIX): com uma Introdução sobre as corporações operárias em Portugal. Lisboa: Empresa do Ocidente, 1900 .

PEREIRA, José Pacheco. Elementos para o estudo da origem do movimento operário no Porto: as associações mutualistas (1850-1870). Lisboa: Fundação Calouste Gulbenkian, 1982.

PEREIRA, José Ribeiro. O Mutualismo e o Estado Novo Corporativo: na Seção de Propaganda promovida pela Comissão Concelhia da Vila do Seixal. Lisboa: Tipográfica, [s.d.].

PERROT, Michelle. Les Ovriers en Grève (1871-1890). Paris: Mouton, 1973.

PIKETTY, Thomas. O capital no século XXI. Rio de Janeiro: Editora Intrínseca, 2014.

PITACAS, José Alberto Pereira. Utilidade social e eficiência do mutualismo. 2009. Dissertação (Mestrado em Economia e Política Social) - Instituto Superior de Economia e Gestão, Universidade Técnica de Lisboa. Lisboa, 2009.

POLANYI, Karl. (1944). The great transformation. Boston: Beacon Press, 1968.

QUELHAS, Ana Paula do Canto Lopes Pires Santos. A refundação do papel do Estado nas políticas sociais; a alternativa do movimento mutualista. Dissertação (Mestrado em Sociologia) - Faculdade de Economia, Universidade de Coimbra. Coimbra 1999. 
RALLE, Michel. A função da proteção mutualista na construção de uma identidade operária na Espanha (1870-1910), Cadernos AEL: Sociedades Operárias e Mutualismo. Campinas: IFCH/UNICAMP, v. 6, n. 10/11, p. 13-38, 1999.

RAMOS, António Alberto C. P. As coletividades de Almada (1890-1910); associativismo do tipo cultural e recreativo - tentativa de abordagem ao seu estudo. Almada: Gráfica Ideal Cacilhas, 1991.

RECALDE, Héctor. Beneficencia, assistencialismo estatal y previsón social. Buenos Aires: Centro Editor de America Latina, 1991.

RODRIGUES, Edgar. Breve história do pensamento e das lutas sociais em Portugal. Lisboa: Assírio \& Alvim, 1977. . O despertar operário em Portugal (1834-1911). Lisboa: Sementeira, 1980.

RODRIGUES, José Albertino. Sindicato e desenvolvimento no Brasil. São Paulo: Difusão Europeia do Livro, 1968.

ROSENDO, Vasco. O Mutualismo em Portugal: dois séculos de história e suas origens. Lisboa: Montepio Geral, 1996.

RUIVO, Beatriz; LEITÃO, Eugênio. O sindicalismo do funcionalismo público na I República. Lisboa: Seara Nova, 1977.

SAID, Edward W. Culture and imperialism. New York: Vintage Books, 1994.

SAMUEL, R. Village, life and labour. London: Routledge \& Kegan Paul, 1975.

SANTOS, Dina Maria Serrano. Do Mutualismo ao Mercado: a Banca Mutualista em Portugal; estudo de caso: o crédito agrícola mútuo. 2012. Dissertação (Mestrado em Sociologia Económica e das Organizações) - Faculdade de Ciências Sociais e Humanas, Universidade Nova de Lisboa, Lisboa, 2012.

SANTOS, Fernando Piteira. O Centenário da Sociedade “A Voz do Operário”. Lisboa: Sociedade de Instrução e Beneficência “A Voz do Operário”, 1983.

SANTOS, Luiz da Costa. O mutualismo na organização social moderna: conferência da "Semana Mutualista" organizada pelo jornal "O Século" e realizada em 21 de Janeiro de 1933, na Associação dos Empregados do Estado, a convite da Caixa de Sobrevivência "O Futuro". Lisboa: Revista Portuguesa de Seguros, 1933.

SANTOS, Raul Esteves dos. 1879-1894 A vida da Voz do Operário: da fundação do jornal à inauguração das primeiras escolas. Lisboa: Sociedade de Instrução e Beneficência "A Voz do Operário", 1932.

. A grande epopeia dos humildes. Lisboa: Sociedade de Instrução e Beneficência "A Voz do Operário", 1933.

. O Tenente-Coronel João Luiz de Moura e a Voz do Operário. Lisboa: Edição Fora do Mercado, 1939.

SANTOS, Victor. Mutualismo; poderoso auxiliar do Estado no arranjo social da Nação; Palestra realizada na sessão solene de comemoração do 84ㅇaniversário da Associação de Socorros Mútuos dos Empregados do Comércio e da Indústria de Lisboa em 6 de Novembro de 1938. Lisboa: [s.n.], 1941.

SARAIVA, Ana Paula Rocha da Costa. Associativismo mutualista em Lisboa na segunda metade do século XIX. 2011. Dissertação (Mestrado em História) ISCTE - Instituto Universitário de Lisboa, Lisboa, 2011. 
SEWELL JR., William H. Work and Revolution in France: the language of labor from the old regime to 1848. Cambridge: Cambridge University Press, 1980.

SILVA JR., Adhemar Lourenço da. As sociedades de socorros mútuos: estratégias privadas e públicas (estudo centrado no Rio Grande do Sul-Brasil, 1854-1940). 2004. Tese (Doutorado em História) - Faculdade de Filosofia e Ciências Humanas, Pontifícia Universidade Católica do Rio Grande do Sul, Porto Alegre, 2004.

SILVA, Fátima Geraldes da. Associações desportivas, recreativas e culturais: o caso de Covilhã. 2002. Dissertação (Mestrado em Sociologia) - Universidade da Beira Interior. Covilhã, 2002.

SILVEIRA, Jorge. O mutualismo em Portugal; elementos de caráter geral das associações mutualistas. Lisboa: União das Mutualidades Portuguesas, 1986.

SIMÃO, Azis. Sindicato e Estado: suas relações na formação do proletariado de São Paulo. 2. ed. São Paulo: Ática, 1981.

SOARES, Francisco Sousa. Internacionalização e descentralização: contributos do associativismo. Lisboa: Ingenium, 2003.

SOUSA, Luís de. Mutualismo: conferência realizada na Associação Comercial de Angra do Heroísmo. Angra do Heroísmo: Livraria Andrade, 1933.

SOUSA, Manuel Joaquim de. O sindicalismo em Portugal: esboço histórico. Lisboa: Comissão Escola e Propaganda do Sindicato do Pessoal da Câmara da Marinha Mercante Portuguesa, 1931.

. O sindicalismo em Portugal. 3. ed. Porto: Afrontamento, 1972.

TARRACHA, Jorge Câncio. Antologia histórica sobre o movimento associativo de Vila Franca de Xira, 1853-1995. Alhandra: Gráfica Alhandrense, 1997.

TAVARES, Virgílio. O centenário da associação de socorros mútuos dos artistas mirandelenses. Guimarães: Editora Cidade Berço, 2001.

THOMPSON, E. P. The making of the english working class. New York: Vintage Books, 1966.

TILLY, L.; SCOTT, J. W. Women, work and family. New York: Holt, Rinehart and Winston, 1978.

VENTURA, Maria da Graça A. Mateus (Org.). O Associativismo. Das Confrarias e Irmandades aos Movimentos Sociais Contemporâneos. Lisboa: Edições Colibri, 2006.

VIANNA, Luiz Werneck. Liberalismo e sindicato no Brasil. 2. ed. Rio de Janeiro: Paz e Terra, 1978.

VILAÇA, Helena Carlota Ribeiro. Associativismo e movimentos sociais; modalidades de participação. 1993. Tese (Doutorado em Sociologia) - Faculdade de Letras da Universidade do Porto, Porto, 1993.

VISCARDI, Cláudia Maria Ribeiro. O teatro das oligarquias; uma revisão da política do café com leite. Belo Horizonte: C/Arte, 2001.

. Mutualismo e Filantropia, Locus: Revista de História, Juiz de Fora, v. 10, n. 1, 99-113, jan.-jun., 2004.

. As experiências mutualistas em Minas Gerais: um ensaio interpretativo. In: ALMEIDA, Carla M. Carvalho de; OLIVEIRA, Mônica Ribeiro de. (Orgs.). Nomes e números: alternativas metodológicas para a história econômica e social. Juiz de Fora: Ed. UFJF, 2006, p. 305-322. 
. Experiências da prática associativa no Brasil (1860-1880), Topoi: Revista de História, Programa de Pós-Graduação em História Social da UFRJ, v. 9, n. 16, p. 117-136, jan.-jun. 2008.

. Estratégias Populares de Sobrevivência: Mutualismo e Filantropia no Rio de Janeiro Republicano. Revista Brasileira de História, v. 29, p. 291-315, 2009.

. JESUS, Ronaldo P. de. A experiência mutualista e a formação da classe trabalhadora no Brasil. In: FERREIRA, Jorge; REIS FILHO, Daniel Aarão (Orgs.). As esquerdas no Brasil. Rio de Janeiro: Civilização Brasileira, 2007. Vol. 1: A formação das tradições. p. 21-51.

VITORINO, Artur J. R. Máquinas e Operários: mudança técnica e sindicalismo gráfico (São Paulo e Rio de Janeiro, 1858-1912). São Paulo: Annablume/FAPESP, 2000.

Recebido: 19 de abril de 2016 Aprovado: 07 de junho de 2016

\section{Autor/Author:}

RONALDO PEREIRA DE JESUs <ronaldo.jesus@ufjf.edu.br>

- Professor Associado do Departamento de História e do Programa de Pós-Graduação em História da Universidade Federal de Juiz de Fora (UFJF); Doutor em História Social pela Universidade de São Paulo (USP); autor de Visões da Monarquia; escravos, operários e abolicionismo na Corte (Argvmentvm, 2009), Resistência e integração; as classes trabalhadoras e a criação do sindicato único e oficial no Rio de Janeiro (Editora UFOP, 2012), Associativismo entre portugueses no Rio de Janeiro imperial (UNICAMP, 2014) e Marxism and Brazilian Historiography (Routledge, 2015); Pesquisador do Laboratório de História Política e Social (LAPHS- UFJF).

- Associate Professor at the Department of History of the Post-Graduation Program in History of the Universidade Federal de Juiz de For a (UFJF); PhD in Social History by the Universidade de São Paulo (USP; author of Visões da Monarquia; escravos, operários e abolicionismo na Corte (Argvmentvm, 2009), Resistência e integração; as classes trabalhadoras e a criação do sindicato único e oficial no Rio de Janeiro (Editora UFOP, 2012), Associativismo entre portugueses no Rio de Janeiro imperial (UNICAMP, 2014) e Marxism and Brazilian Historiography (Routledge, 2015); researcher at the Political and Social History Laboratory (LAPHS- UFJF). 